Slavica

bruxellensia

\section{Slavica bruxellensia}

Revue polyphonique de littérature, culture et histoire

slaves

9 | 2013

Érotisme

\title{
Homosexualita v dějinách české kultury (L'Homosexualité dans l'histoire de la culture tchèque), sous la direction de Putna M. C. et alii
}

\section{Xavier Galmiche}

\section{(2) OpenEdition}

Édition électronique

URL : http://journals.openedition.org/slavica/1354

DOI : 10.4000/slavica.1354

ISSN : 2034-6395

Éditeur

Université libre de Bruxelles - ULB

Référence électronique

Xavier Galmiche, « Homosexualita v dějinách české kultury (L'Homosexualité dans l'histoire de la culture tchèque), sous la direction de Putna M. C. et alii », Slavica bruxellensia [En ligne], 9 | 2013, mis en ligne le 15 avril 2013, consulté le 22 septembre 2020. URL : http://journals.openedition.org/slavica/ 1354 ; DOI : https://doi.org/10.4000/slavica.1354

Ce document a été généré automatiquement le 22 septembre 2020.

\section{(†) $\ominus$}

Les contenus de Slavica bruxellensia sont mis à disposition selon les termes de la Licence Creative Commons Attribution - Pas d'Utilisation Commerciale - Pas de Modification 3.0 France. 
Homosexualita v dějinách české kultury (L'Homosexualité dans l'histoire de la culture tchèque), sous la direction de Putna M. C. et alii

Xavier Galmiche

\section{RÉFÉRENCE}

Homosexualita $v$ dějinách české kultury, sous la direction de Putna M. C. et alii, Academia, Prague, 2011, 494 p. 
1 Trois parutions collectives conçues simultanément (et issues d'un même colloque tenu en 2009, certains auteurs s'y retrouvant dans des proportions variées) apportent, à partir de points de vue complémentaires, un éclairage sur l'homosexualité dans les Pays tchèques, champ de recherches laissé particulièrement en jachère.

2 Avant d'aborder le principal ouvrage, il me faut m'arrêter sur les deux autres.

Od žalářre $k$ oltáři : emancipace homosexuality

$v$ českých zemích od roku 1867 do současnosti(Du cachot à l'autel l'émancipation de l'homosexualité en Pays tchèques de 1867 à nos jours), le second en terme de date de parution, retrace de manière chronologique les conditions

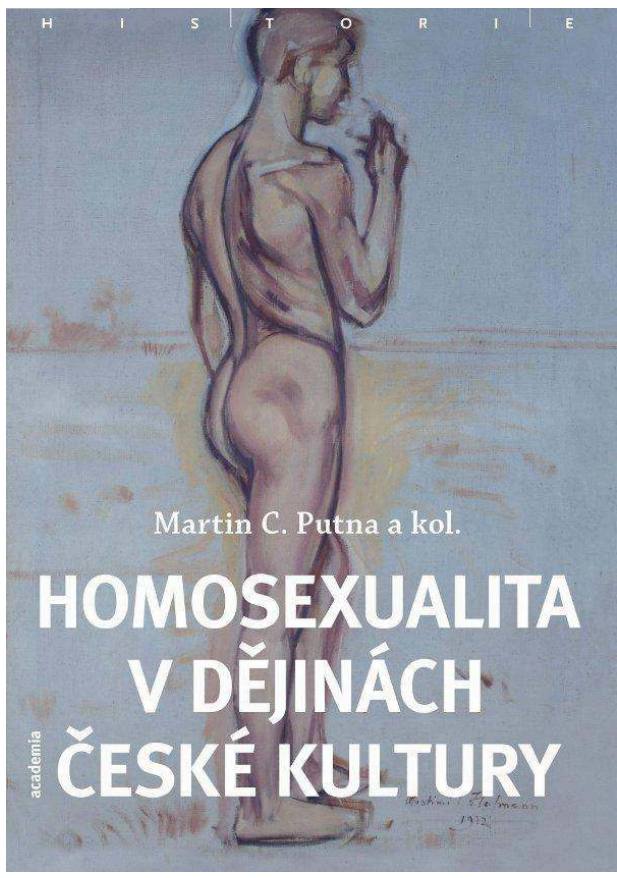
juridico-politiques d'une reconnaissance sociale de l'homosexualité : il passe en revue quelque 150 ans de mutations, depuis l'époque de l'empire austro-hongrois jusqu'à l'adoption en 2006 du «partenariat enregistré ", la forme légale d'union civile entre homosexuels actuellement en vigueur en République tchèque - le titre de l'ouvrage indiquant aussi la possible perspective d'une accession au mariage. Il s'agit essentiellement de l'histoire d'un mouvement militant, recensant les groupes et mouvements souvent dispersés ayant contribué à la naissance d'un espace spécifique dans la société, d'un débat dans l'opinion et d'une adaptation des cadres légaux garantissant l'égalité des droits : un travail d'historien certes, mais quelques fois raconté sur le ton du reportage, relatant parfois d'heure en heure le combat législatif de 2006. Malgré l'ample documentation juridique et la clarté des concepts, on regrette un peu que ne soient pas évoqués les débats psychologiques et spirituels induits dans la société par l'irruption de la thématique homosexuelle, notamment dans les cercles qui n'y sont a priori pas favorables, notamment la sphère religieuse. L'autre ouvrage, encore à paraître, intitulé Miluji tvory svého pohlaví. Homosexualita $v$ dějinách a společnosti českých zemí (J'aime les êtres de mon sexe. L'homosexualité dans l'histoire et la société des Pays tchèques), devrait couvrir les aspects sociologiques de la question.

Venons-en au fait. Homosexualita $v$ dějinách české kultury (L'Homosexualité dans l'histoire de la culture tchèque) est un épais volume paru en 2011. L'initiative de la publication ainsi que la responsabilité du volume et de la préface reviennent au critique académique, mais aussi écrivain et essayiste Martin C. Putna, hyperactif de la plume, inventif et prolifique (ce qui a ses inconvénients, les textes n'ayant pas toujours une qualité stylistique à la hauteur de la réflexion et de l'information qui y sont développées). Putna livre ici, pour ainsi dire dissimulé dans une publication collective, tout un livre personnel: pas moins de quatre articles et une introduction méthodologique de plus de cinquante pages. Celle-ci constitue un très utile rappel de l'histoire occidentale des combats pour la reconnaissance des droits des homosexuels et, de façon schématique, de leur inscription dans un pôle majeur de l'histoire 
culturelle respective de trois pays décisifs pour cette question: combat politique " américain » (i.e. états-unien), combat culturel français, combat scientifique allemand. Cette présentation se clôt sur un panorama des méthodes d'analyse de la «culture homosexuelle ».

Un ouvrage pionnier, donc: sa structure s'en ressent. La façon dont les textes composant le volume sont répartis (selon les domaines suivants: littérature, arts plastiques, théâtre et cinéma, ce qui n'empêche pas certains articles de viser certaines analyses synesthésiques) semble être une façon pour les auteurs d'annoncer qu'il s'agit, sans volonté d'exhaustivité, de procéder à un tour d'horizon, en assumant l'aspect du catalogue. Nous suivons ici ce parti pris et nous contentons de dresser la liste des sujets abordés, avant de nous attarder, faute de place, à la seule époque de la décadence littéraire, fondamentale pour la question.

Dans la première partie, littéraire, les analyses de Putna (« Sodomites, amis spirituels et amazones; ce qu'il y avait avant l'homosexualité », qui tente d'imposer la distinction sémantique - à mes yeux problématique - entre les faits "homoérotiques" et l'«homosexualité », qui n'existerait en tant que telle qu'à partir de son affirmation dans l'espace social, et "L'homosexualité dans la littérature tchèque moderne ») occupent une belle part; elles sont suivies de trois textes: l'un sur un auteur germanophone de Bohême, qui accompagna sa communauté en exil, «le cas Josef Mühlberger. Notes sur le phénomène du 'camouflage homoérotique' littéraire » (Lukáš Motyčka), reposant notamment sur une remarquable critique thématique des motifs « homo-connotés » (le marais, l'étang, l'île, la mer, par exemple dans le récit le plus connu de Mühlberger, Die Knaben und der Fluss) ; pour leur part, « La génération de Hlas : la littérature tchèque homoérotique de l'entre-deux-guerres et ses créateurs » (Roar Lishaugen \& Jan Seidl) et "Vingt ans de lutte pour une littérature homosexuelle populaire» (Michael Čuř́n) retracent la diffusion plus ou moins heureuse de la thématique depuis 1989.

Le chapitre «Beaux-Arts" énumère les thèmes suivants: "Possibilités d'une interprétation queer de l'art tchèque ancien » (Hynek Látal) ; « 'Rejeton poussé de biais'. Images de l'homosexualité dans l'art de la décadence tchèque.» (Ladislav ZikmundLender); “'En apparence, Jeník petit garçon était comme les autres'. Jan Zrzavý, l'équivalent artistique du 'chemin de la sublimation'» (Martin C. Putna); "Ten-TaToyen. Image de ce sur quoi on se tait », sur l'artiste Toyen, née Marie Čermínová, associée au mouvement surréaliste (Milena Bartlová); "Des agnostiques normaux? L'art contemporain tchèque et visualité queer » (Zuzana Štefková) ; « Un jeune homme assis sur la rive du goût tchèque. Homosexualité et genres artistiques populaires » (Ladislav Zikmund-Lender).

8 Plus succincte, la partie " Théâtre et cinéma » inclut quant à elle " Moments de la vie et de l'œuvre de Václav Krška jusqu'en 1945 » (Lukás Nozar) ; « L'homosexualité, thème du théâtre tchèque contemporain » (Jan Kerbr) et « De Krška à Troška. L'homosexualité et le cinéma tchèque » (Martin C. Putna).

Comme on le voit, la proportion d'articles prosopographiques est importante, comme c'est souvent le cas d'ouvrages issus d'un colloque. Cela peut générer quelques problèmes, mais plutôt du côté du lecteur: en découvrant l'importance de l'homosexualité dans la vie de personnalités particulières, jusque dans l'anecdote de leur biographie, il peut en effet céder à la «tentation de la liste » (l'établissement du répertoire de " ceux qui y en sont »), assorti du réflexe - après tout pas très élégant - 
«Tiens, tiens! lui aussi...». Pourtant, la méthode monographique est légitime, et instructive au sujet de créateurs que la pression sociale poussa à refouler leur homosexualité ou en tous cas à ne pas l'assumer, et qui n'ont laissé sur cette piste que des indices (c'est le cas du peintre Zrzavý ou encore de Mühlberger).

Pour le reste, on hésite parfois entre l'enthousiasme face à de vraies révélations et une certaine gêne causée par quelques approximations dans la nécessaire synthèse entre les recherches sur l'homosexualité et l'histoire culturelle générale. Concentrons-nous ici sur l'époque de la décadence (vers 1900), dont on sait qu'elle a suscité dans les Pays tchèques, sur fond de crises existentielles, des réalisations remarquables, que de nombreux catalogues d'expositions édités depuis vingt ans ont permis de redécouvrir: sur des revues (Moderní revue, Voné směry), des groupes artistiques (notamment Sursum), sur l'art de l'école catholique moderne), et des personnalités comme Jiř́ Karásek ze Lvovic, qui fit un peu figure d'Oscar Wilde de Bohême (deux expositions ont été consacrées en dix ans à sa célèbre collection d'art, la « Galerie Karásek »), etc. Sur cette époque centrale,Ladislav Zikmund-Lender propose une lecture qui réduit le dandysme à l'homosexualité, comme si les termes étaient synonymes, ce qui est manifestement faux. Mais il ouvre radicalement la perspective en esquissant une généalogie philosophico-esthétique de l'attention à l'homosexualité (Arthur Schopenhauer, Sigmund Freud, Alfred Adler, Otto Weininger, etc.) et surtout retrace la circulation du thème homosexuel de l'écrit à l'image. Particulièrement intéressante est son analyse du "réalisme homoérotique ", surtout connu dans la peinture américaine (Thomas Eakins) et dont il relève finement les analogies dans la peinture tchèque: il en voit un prolongement dans le programme iconographique qui accompagna le mouvement patriotique sokol, que soutinrent d'ailleurs Karásek lui-même et son protégé le peintre polonais Wlastimil Hofman, du cercle de Jacek Malczewski.

On peut regretter que, dans ce chapitre, ne soit pas consacré plus que quelques notes à William Ritter, écrivain et essayiste suisse qui, vers 1900, s'amouracha de l'Europe centrale et de ses beaux garçons, et prit pour compagnons (successivement - mais aussi simultanément) un Slovaque (dont il fit d'ailleurs le portrait en compagnie de Hofman) et un Tchèque: outre l'intérêt de sa biographie pour retracer les réseaux d'une naissante sociabilité homosexuelle, Ritter est aussi une clef pour comprendre le poids des images homosexuelles dans l'histoire du goût, par ses textes mais aussi par ses innombrables dessins qui s'intègrent précisément dans le cadre du «réalisme homoérotique ".

Plus généralement, on pourra reprocher à ce livre de ne pas être ce qu'il ne prétend pas être: une approche transfrontalière de l'homosexualité dans les contextes géopolitiques larges dans lesquels s'est successivement inscrite l'histoire des Pays tchèques (Saint Empire Romain Germanique, Vieille Autriche, empire austro-hongrois, mais aussi empire soviétique) : dans des sociétés où l'homosexualité est un délit et/ou un tabou, c'est souvent à l'étranger et en voyage que le passage à l'acte, voire à un mode de vie homosexuel est rendu possible, et il est intéressant de reconstituer la " carte mentale " des lieux favorables à cet assouvissement. Dans sa thèse consacrée aux stratégies socio-poétiques de Karásek ${ }^{1}$, Roar Lishaugen n'a-t-il pas montré les clubs de Vienne comme échappatoire au milieu étriqué des dandys praguois?

Mais à l'inverse, ces textes restituent à la question du statut de l'homosexualité dans les représentations une position cruciale : cette création réputée "en marge » a participé en réalité à l'établissement de valeurs partagées par tous, et parfois même par la 
«nation» (le mouvement Sokol, Zrzavý, etc.). On regrettera à ce sujet que le livret alambiqué de Dalibor, opéra de Bedřich Smetana, créé en 1868 au Théâtre National de Prague pour son inauguration, et présentant un drame amoureux et militaire entre un chevalier rebelle et son ami violoniste Zdeněk, ne soit évoqué qu'en passant. Il est l'exemple par excellence de la présence de l'homosexualité au cœur du canon culturel que seul un travail régulier d'occultation au cours du XXe siècle a pu faire oublier (cet oubli, bien compréhensible dans le contexte de systèmes totalitaire souvent pudibonds, a parfois des conséquences dramatiques: Motyčka défait quelques mythes au sujet de Mühlbeger, qui, piégé par un séducteur maître-chanteur, se lava du scandale en s'engageant dans la Wehrmacht...). En somme, le volume invite à méditer sur le fonctionnement de la balance entre affirmation et occultation, entre identité intime et identité collective - une balance qui a pour nom culture.

\section{BIBLIOGRAPHIE}

Homosexualita $v$ dějinách české kultury (L'Homosexualité dans l'histoire de la culture tchèque), sous la direction de Putna M. C., Academia, Prague, 2011, 494 p.

Seidl J. et alii, Od žalářre k oltáři : emancipace homosexuality v českých zemích od roku 1867 do současnosti (Du cachot à l'autel - l'émancipation de l'homosexualité en Pays tchèques de 1867 à nos jours), Host, Brno, 2012, 582 p.

Miluji tvory svého pohlaví. Homosexualita $v$ dějinách a společnosti českých zemí (J'aime les êtres de mon sexe. L'homosexualité dans l'histoire et la société des Pays tchèques), sous la direction de Himl P., Seidl J. \& Schindler Fr., Argo, Prague (à paraître en 2013).

\section{NOTES}

1. Lishaugen R., Speaking with a Forked Tongue. Double Reading Strategies in Romány tři mágů by Jiří Karásek ze Lvovic, Gothenburg Slavic Studies, Department of Slavic Languages, University of Gothenburg (Suède), 2008.

\section{INDEX}

Index chronologique : XIXe siècle, XXe siècle, XXIe siècle, époque contemporaine Index géographique : République tchèque, Tchécoslovaquie

Mots-clés : homosexualité, histoire slave 


\section{AUTEURS}

\section{XAVIER GALMICHE}

Professeur à l'Université de Paris-Sorbonne (Paris-IV) ; directeur de la section d'Etudes centre européennes (UFR d'Etudes slaves) ; sous-directeur de l'UFR d'Etudes slaves ; co-directeur du Centre de recherches sur les cultures et littératures d'Europe centrale, orientale et balkanique (EA 4084), il en dirige la composante CIRCE (Centre Interdisciplinaire de Recherches CentreEuropéennes) et sa revue, Cultures d'Europe centrale. 